\title{
Hyperhomocysteinaemia in young patients with non-arteritic anterior ischaemic optic neuropathy
}

\author{
Aki Kawasaki, Valerie A Purvin, Richard A Burgett
}

\begin{abstract}
Backgroundlaim-Elevated plasma homocysteine is a newly identified vascular risk factor among patients under age 55 years with cerebrovascular, cardiovascular, or peripheral vascular disease. This study sought to evaluate retrospectively the plasma homocysteine status among healthy younger patients with ischaemic optic disc disease.

Methods-12 non-diabetic patients who had been diagnosed with non-arteritic anterior ischaemic optic neuropathy (NAION) before the age of 50 years were identified from chart review. None had experienced previous ischaemic cerebrovascular, cardiovascular, or peripheral vascular events. Plasma homocysteine, CBC, renal function, vitamin B6, vitamin $B 12$, and folate levels were sampled in the fasting state.

Results-Two of 12 patients (17\%) had hyperhomocysteinaemia. Both had experienced NAION in both eyes with recurrent episodes. Neither patient was hypertensive nor had a smoking history. One of these two patients had mild hypercholesterolaemia which did not warrant medication.
\end{abstract}

Conclusions-Elevated plasma homocysteine may be associated with NAION. An evaluation for hyperhomocysteinaemia should be considered in patients with NAION who do not have the typical risk factor such as older age, diabetes, hypertension, or tobacco use. It should also be considered in young patients with bilateral or recurrent attacks of NAION. (Br f Ophthalmol 1999;83:1287-1290)

Elevated plasma homocysteine is a vascular risk factor that is independent of diabetes, hypertension, cholesterol, and tobacco. ${ }^{12} \mathrm{Ho}-$ mocysteine is an intermediary amino acid formed during the conversion of amino acid methionine to cysteine (Fig 1). Severely elevated plasma homocysteine (100-200 times normal) with spillover into the urine is specifically termed "homocystinuria" and is usually caused by a recessively inherited enzyme deficiency. Homocystinuric patients are symptomatic during childhood with lens disloca- tion, bony abnormalities, developmental delay, and premature vascular events. "Hyperhomocysteinaemia" is a more recent term to indicate mild to moderately elevated plasma homocysteine levels. Hyperhomocysteinaemic patients do not develop lenticular, osseous, or developmental abnormalities yet have increased risk of premature vascular occlusive disease such as peripheral vascular disease, stroke, and myocardial infarction before age 50 years. ${ }^{1-8}$

The prevalence of mild to moderate elevation of plasma homocysteine within the general population is about $5 \% .{ }^{9}$ The prevalence of hyperhomocysteinaemia among non-diabetic patients under age 55 years who have had stroke or myocardial infarction is $20-30 \% .^{2-4}$ Several reports have associated retinal artery and retinal vein occlusion in young patients with hyperhomocysteinaemia. ${ }^{10-12}$

Non-arteritic anterior ischaemic optic neuropathy (NAION) is typically a disorder of older patients who have predisposing vascular and structural optic disc risk factors. Occasionally, NAION occurs in younger, non-diabetic patients who do not have the conventional vascular risk factors such as tobacco use, hyperlipidaemia, or hypertension. We report a series of 12 patients under age 50 years with NAION who were evaluated for hyperhomocysteinaemia.

Materials and methods

All the charts of patients diagnosed with NAION were retrospectively reviewed by either VAP or AK between 1987 and 1997. Criteria for accepting a diagnosis of NAION in these patients were (1) acute monocular visual loss, (2) persistent decrease in visual acuity or visual field defect, (3) optic disc oedema acutely, or (4) lack of a macular star. Patients were excluded with a history of demyelinating optic neuritis, multiple sclerosis, or diabetes mellitus. Patients were also excluded if a sedimentation rate was elevated or renal function (BUN/creatinine) was abnormal. The clinical use of the term "young" is generally defined in the stroke literature as age less than 50-55 years. In our series, we identified 17 patients who were under age 50 years at the time of their NAION diagnosis and 12 of these "young" NAION patients were available for additional serological testing. 
Table 1 Summary of visual data in 12 young patients with non-arteritic anterior ischaemic optic neuropathy

\begin{tabular}{|c|c|c|c|c|c|c|c|c|c|}
\hline \multirow[b]{2}{*}{ Patient } & \multirow{2}{*}{$\begin{array}{l}\text { Age at } \\
1 s t \\
\text { AION } \\
\text { (years) }\end{array}$} & \multirow{2}{*}{$\begin{array}{l}\text { Involved } \\
\text { eye }\end{array}$} & \multirow[b]{2}{*}{ Initial VA } & \multirow{2}{*}{$\begin{array}{l}\text { Initial visual field defect } \\
\text { of involved eye }\end{array}$} & \multirow{2}{*}{$\begin{array}{l}\text { Involvement of } \\
\text { contralateral } \\
\text { eye? }\end{array}$} & \multicolumn{2}{|c|}{ Final VA } & \multicolumn{2}{|l|}{ Final VF } \\
\hline & & & & & & $R E$ & $L E$ & $R E$ & $L E$ \\
\hline 1 & 48 & $\mathrm{RE}$ & $20 / 20$ & Inferior altitudinal & & $20 / 400$ & $20 / 20$ & $\begin{array}{l}\text { Inferior altitudinal and } \\
\text { central scotoma }\end{array}$ & WNL \\
\hline 2 & 32 & $\mathrm{RE}$ & $20 / 15$ & Inferior altitudinal & & $20 / 15$ & $20 / 15$ & Inferior altitudinal & WNL \\
\hline 3 & 26 & $\mathrm{RE}$ & $20 / 200$ & Inferior altitudinal & & $20 / 200$ & $20 / 20$ & $\begin{array}{l}\text { Inferior altitudinal and } \\
\text { cecocentral scotoma }\end{array}$ & WNL \\
\hline 4 & 44 & $\mathrm{RE}$ & $\mathrm{CF}$ & $\begin{array}{l}\text { Central scotoma, } \\
\text { nasal loss }\end{array}$ & 7 years later & $\begin{array}{l}20 / \\
50-2\end{array}$ & $\mathrm{CF}$ & $\begin{array}{l}\text { Absolute superior } \\
\text { altitudinal with relative } \\
\text { inferior scotoma }\end{array}$ & Absolute central scotoma \\
\hline 5 & 37 & LE & $20 / 15$ & Inferior altitudinal & & $20 / 15$ & $20 / 15$ & WNL & Inferior altitudinal \\
\hline 6 & 21 & $\mathrm{RE}$ & $20 / 70$ & Central scotoma & $\begin{array}{l}16 \text { years later } \\
\text { and } 22 \text { years } \\
\text { later }\end{array}$ & $20 / 60$ & CF OS & Central scotoma, nasal loss & Temporal island \\
\hline 7 & 23 & LE & $20 / 20$ & Superior nasal step & & $20 / 15$ & $20 / 20$ & WNL & Superior nasal step \\
\hline 8 & 29 & $\mathrm{RE}$ & $20 / 15$ & Inferonasal depression & 6 years later & $20 / 15$ & $20 / 25-2$ & Inferior altitudinal & $\begin{array}{l}\text { Superonasal scotoma, } \\
\text { inferior altitudinal }\end{array}$ \\
\hline 9 & 42 & RE & $20 / 20$ & $\begin{array}{l}\text { Inferior altitudinal } \\
\text { scotoma }\end{array}$ & & $20 / 20$ & $20 / 15$ & Inferior altitudinal scotoma & WNL \\
\hline 10 & 47 & LE & $\mathrm{CF}$ & Cecocentral scotoma & & $20 / 15$ & $20 / 50$ & Inferonasal depression & Caecocentral scotoma \\
\hline 11 & 39 & $\mathrm{RE}$ & $20 / 20$ & Inferior altitudinal & 6 Years later & $20 / 20$ & $20 / 20$ & Inferior altitudinal & Inferonasal \\
\hline 12 & 45 & $\mathrm{RE}$ & $20 / 20$ & Inferior altitudinal & $\begin{array}{l}12 \text { years later } \\
\text { and } 13 \text { years } \\
\text { later }\end{array}$ & $20 / 20$ & $20 / 30$ & Inferior altitudinal & $\begin{array}{l}\text { Inferior altitudinal, } \\
\text { superior paracentral } \\
\text { scotoma }\end{array}$ \\
\hline
\end{tabular}

Table 2 Summary of laboratory values in 12 young patients with non-arteritic anterior ischaemic optic neuropathy

\begin{tabular}{|c|c|c|c|c|c|c|c|}
\hline Patient & $\begin{array}{l}\text { BUN/ } \\
\text { Creat }\end{array}$ & $\begin{array}{l}\text { Haematocrit } \\
(\%)\end{array}$ & $\begin{array}{l}\text { Serum folate } \\
(1.5-20.6 \mathrm{ng} / \mathrm{ml})\end{array}$ & $\begin{array}{l}\text { RBC folate } \\
(95-570 \mathrm{ng} / \mathrm{ml})\end{array}$ & $\begin{array}{l}B_{6} \\
\text { (reference range in } n g / m l \text { ) }\end{array}$ & $\begin{array}{l}B_{12} \\
(211-911 \mathrm{pg} / \mathrm{ml})\end{array}$ & $\begin{array}{l}\text { Homocysteine } \\
\text { (reference range in } \mu \mathrm{mol} / \mathrm{l})\end{array}$ \\
\hline $1 \dagger$ & $9 / 1.0$ & 44.9 & 2.8 & 169 & $14.6(12.7-34.3)$ & $204^{\star}$ & $15.9(7-22)$ \\
\hline $2 \dagger$ & $18 / 1.0$ & 48.6 & 7.7 & 459 & $15.6(7-52)$ & 467 & $7.2(7-22)$ \\
\hline $3 \dagger$ & $9 / 0.7$ & 37.5 & 5.7 & 147 & $8.2(2-26)$ & 333 & $10.2(7-22)$ \\
\hline $4 \dagger$ & $10 / 0.8$ & 44.2 & 7.0 & 191 & $6.6(2-26)$ & 441 & $8.8(7-22)$ \\
\hline $5+$ & $15 / 1.3$ & 45.2 & 7.5 & 279 & $32(7-52)$ & 347 & $13.5(7-22)$ \\
\hline $6 \dagger$ & & 41.3 & 10.1 & 403 & $5.2^{\star}(12.7-34.3)$ & 428 & $5.7(7-22)$ \\
\hline $7 \dagger$ & $17 / 1.0$ & 45.3 & 10.0 & 461 & $17.8(7-52)$ & 616 & $6.9(7-22)$ \\
\hline $8 t$ & & & & & $7.4(7-52)$ & 521 & $9.9(7-22)$ \\
\hline $9 \dagger$ & & & & 604 & & 512 & $9.3(7-22)$ \\
\hline $10 \ddagger$ & & 39.9 & & & & & $13.0(2.8-13.5)$ \\
\hline $11 \ddagger$ & $14 / 1.1$ & 46.5 & 3.6 & 249 & $10.5(7-52)$ & 282 & $29.5^{\star}(2.8-13.5)$ \\
\hline $12 \ddagger$ & & 43.0 & & & & & $16.1^{\star}(2.8-13.5)$ \\
\hline
\end{tabular}

${ }^{\star}$ Indicates abnormal value. †Data from Corning Nichols Institute, San Juan Capistrano, CA, USA. ‡Data from Quest Diagnostics, San Juan Capistrano, CA, USA.

All 12 patients were evaluated for a fasting plasma homocysteine level using automated high performance liquid chromatography. However, patients 10,11, and 12 were tested with a different assay kit so the normative reference range given in Table 2 is different. As there is no international standardisation of a normal range of plasma homocysteine, each reference range is established individually by the assay manufacturer. Ten patients had B12 level and haematocrit determination. Nine patients had B6, serum folate, and RBC folate determinations. Blood samples were collected in the fasting state and all tests were performed from a single blood sample per patient. Three of the 12 patients were tested within 1 month of visual loss. None of the patients was taking vitamin supplements, folate, or medications known to influence plasma homocysteine levels.

\section{Results}

There were 10 men and two women. The age at onset of the first episode of NAION ranged from 21 to 47 years. No patient had a recurrence in the first involved eye. NAION was eventually diagnosed in the contralateral eye in five patients $(40 \%)$ over a 6-16 year period (patients $4,6,8,11,12$ ). We additionally documented recurrent episodes in two of these five patients $(6,12)$. Patient 3 reported transient altitudinal visual loss of the previously uninvolved eye lasting 30 minutes.

At time of first diagnosis of NAION, two patients $(10,11)$ demonstrated optic disc pallor, inferonasal visual field depression, and normal visual acuity in the uninvolved eye without a history of visual loss. If we considered this constellation of findings to represent a subclinical episode of NAION in these two patients, then six of 12 patients $(50 \%)$ had bilateral NAION and three of 12 patients $(25 \%)$ had recurrent episodes (patients 6, 11, 12).

Also at the time of first diagnosis of NAION, cup to disc ratio in the contralateral, uninvolved eye was estimated in six patients (patients 1,2, $3,4,7,9)$. Three had cup to disc ratio of 0.0 , two had 0.1 , and one had 0.2. The visual data of all 12 patients are summarised in Table 1 .

Other vascular risk factors were noted. Patient 6 was a known hypertensive under treatment before NAION, while patient 7 was diagnosed with hypertension during his NAION evaluation. Patients 4, 6, 7, and 12 had mild hypercholesterolaemia (212-284 mg/ dl) not requiring medication. Patients 4 and 10 were smokers. Patient 5 had ankylosing spondylitis that was in remission at the time of his NAION. Patient 9 had elevation of angiotensin converting enzyme with normal lysozyme, chest radiography, lung gallium scan, head and orbit magnetic resonance imaging. 


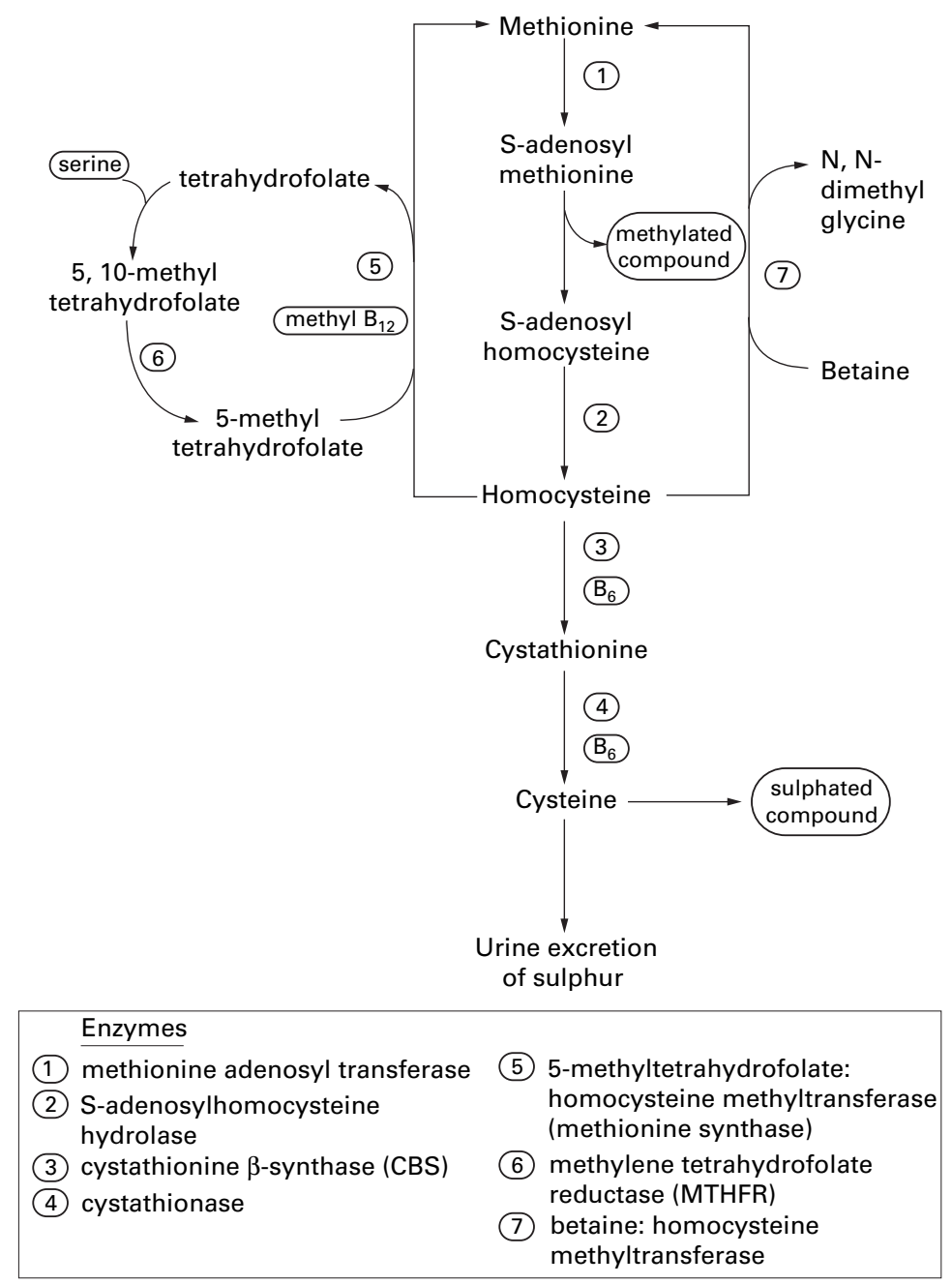

Figure 1 Metabolic pathway of homocysteine.

Two of 12 patients (17\%) had elevated fasting plasma homocysteine levels of $29.5 \mu \mathrm{mol} / 1$ and $16.1 \mu \mathrm{mol} / 1$ (patients 11,12 ). None of the patients evaluated for folate deficiency had abnormalities of haematocrit, serum folate, or RBC folate. However, patient 6 had a low B6 level and patient 1 had a low B12 level. Neither of these two patients had a macrocytic anaemia nor an elevated homocysteine. The laboratory studies and normative ranges are summarised in Table 2.

\section{Discussion}

Homocysteine is an intermediary amino acid formed during the conversion of amino acid methionine to cysteine, known as the methionine trans-sulphuration pathway. Methionine, an essential sulphur containing amino acid, is demethylated to form homocysteine. This is the only metabolic pathway to form homocysteine. ${ }^{3}$ Under normal physiological conditions, there is very little intracellular and plasma homocysteine because it is rapidly metabolised in one of two pathways: (1) continuation in the methionine transsulphuration pathway which serves to transfer the sulphur atom to other compounds and/or excrete it into the urine, or (2) diversion into a remethylation pathway which serves to reconstitute and conserve methionine (Fig 1).

The enzymes in the trans-sulphuration of homocysteine require vitamin B6 as cofactor. The enzymes in the remethylation pathway require vitamins B12 and folate as cofactors. Plasma homocysteine accumulates when there is either a genetic disorder causing an enzyme defect or a nutritional deficiency of a vitamin cofactor (B6, B12, folate). Among the vitamin cofactors, folate status has the strongest inverse relation to homocysteine levels - that is, the lower the folate level the higher the homocysteine level. ${ }^{9} 1314$

The pathophysiological mechanism of homocysteine associated arterial and venous thrombosis is not fully elucidated. Small, medium, and large vessels are involved. Clinical and experimental evidence has suggested both direct toxicity to endothelial cells and a synergistic interaction between homocysteine and lipoproteins. Various platelet abnormalities have also been reported, including increased adhesiveness, decreased survival, and increased thromboxane A activity. A prevailing hypothesis is that homocysteine promotes the clotting cascade via several actions: inactivation of protein $\mathrm{C}$, activation of coagulation factor $\mathrm{V}$, increased vascular smooth muscle proliferation, and inhibition of thrombomodulin. ${ }^{23}$

The association between elevated plasma homocysteine and early vascular occlusive disease is well established. Mild to moderate hyperhomocysteinaemia is an independent risk factor similar to smoking or hyperlipidaemia for peripheral vascular disease, stroke, and myocardial infarction among patients under age 55 years. ${ }^{1-8}$ Hyperhomocysteinaemia has been implicated as a cause of retinal artery and retinal vein occlusions in young patients. Wenzler et al reported a series of 19 patients without diabetes, hypertension, or cardiac disease with a history of retinal artery occlusion or retinal vein occlusion before age 50 years. ${ }^{10}$ They found that four of their 19 (21\%) patients had elevated homocysteine levels; moreover, two of these four hyperhomocysteinaemic patients had had recurrent and bilateral retinovascular occlusive disease (recurrent branch retinal artery occlusions). Biousse et al described a 24 year old man with bilateral central retinal vein occlusions who was found to be hyperhomocysteinaemic. ${ }^{11}$

In our series of 12 young, non-diabetic patients with ischaemic optic disc disease, we identified two patients (patients 11 and 12) with mildly elevated plasma homocysteine. Both eventually experienced bilateral and recurrent episodes of NAION. Patient 11 had NAION in his right eye at age 39; at that time, optic disc pallor with an inferonasal visual field defect was noted in his left eye (presumably a previous subclinical episode of NAION). Six years later, he had a documented episode of NAION in his left eye at 45 years. Patient 12 had three clinical episodes of acute painless visual field loss since age 45 years. Both patients started folate supplementation with normalisation of plasma homocysteine within 
2 months; neither had a recurrent ischaemic event at the 2 year follow up.

We utilised a fasting plasma homocysteine test but recognise that a single homocysteine determination detects only about $60 \%$ of cases of mild to moderate hyperhomocysteinaemia. ${ }^{12}$ Sensitivity for detecting abnormalities of homocysteine metabolism may be increased by administering an oral methionine load to uncover "latent" hyperhomocysteinaemia, analogous to the glucose tolerance test. An adjunctive test is the polymerase chain reaction to detect a genetic defect in the enzyme methylene tetrahydrofolate reductase (MTHFR). This thermolabile variant of MTHFR is an increasingly recognised cause of hyperhomocysteinaemia. ${ }^{13}{ }^{14}$ If these additional tests are performed, the prevalence of hyperhomocysteinaemia in young patients with NAION may be higher than we detected (two of 12 , or $17 \%$ )

An obvious limitation of our study is the small number of patients without a control group. Based on such a small sample size, we do not suggest that $17 \%$ of all patients with NAION who are under age 50 years will have hyperhomocysteinaemia but we do hope to raise awareness for other possible metabolic/ haematological risk factors of ischaemic optic neuropathy when the typical vascular associations such as diabetes, hypertension, etc are absent. Another limitation of this study was the utilisation of two different laboratories for homocysteine determination which may lead to laboratory bias. Nevertheless, this is the first report of hyperhomocysteinaemia associated with NAION. We hope that our findings might prompt further investigation of this association in a larger, prospective series of patients, as elevated homocysteine is now established as a risk factor for stroke, myocardial infarction, and peripheral vascular disease.

The authors have no proprietary interests in any of the instrumentation used in this study.

1 D'Angelo A, Selhub J. Homocysteine and thrombotic disease. Blood 1997;90:1-11.

2 The European Concerted Action Project. Plasma homocysteine as a risk factor for vascular disease. $7 A M A$ 1997;277:1775-81.

3 Mayer EL, Jacobsen DW, Robinson K. Homocysteine and coronary atherosclerosis. $\mathcal{F}$ Am Coll Cardiol 1996;27:51727.

4 Clarke R, Daly L, Robinson K, et al. Hyperhomocysteinemia: an independent risk factor for vascular disease. N Engl F Med 1991;324:1149-55.

5 Stamfer MJ, Malinow MR, Willet WC, et al. A prospective study of plasma homocyst(e)ine and risk of myocardial infarction in US physicians. $\mathscr{f} A M A 1992 ; 268: 877-81$.

6 Heijer MD, Koster T, Blom HJ, et al. Hyperhomocysteinemia as a risk factor for deep-vein thrombosis. N Engl f Med mia as a risk factor

7 Coull BM, Malinow MR, Beamer N, et al. Elevated plasma homocyst(e)ine concentration as a possible independent risk factor for stroke. Stroke 1990;21:572-6.

8 Boushey CJ, Beresford SAA, Omenn GS, et al. Plasma homocysteine as a risk factor for vascular disease. $\mathcal{F} A M A$ 1995;274:1049-57.

9 Selhub J, Jacques PF, Wilson PWF, et al. Vitamin status and intake as primary determinants of homocysteinemia in an elderly population. FAMA 1993;270:2693-8.

10 Wenzler EM, Rademakers AJJM, Boers GHJ, et al. Hyperhomocysteinemia in retinal artery and retinal vein occlusion. Am f Ophthalmol 1993;115:162-7.

11 Biousse V, Newman NJ, Sternberg P Jr. Retinal vein occlusion and transient monocular visual loss associated with hyperhomocystenemia. Am f Ophthalmol 1997;124:25760 .

12 Loewenstein A, Winder A, Goldstein M et al. Bilateral retinal vein occlusion associated with 5,10-methylenetetrahydrofolate reductase mutation. Am f Ophthalmol 1997;124:840-1.

13 Engbersen AMT, Franken DG, Boers GHJ, et al. Thermolabile 5, 10-methylenetetrahydrofolate reductase as a cause of mild hyperhomocysteinemia. Am f Hum Genet 1995;56: 142-50.

14 Jacques PF, Bostom AG, Williams RR, et al. Relation between folate status, a common mutation in methylenetetrahydrofolate reductase, and plasma homocysteine concentrations. Circulation 1996;93:7-9. 